\title{
Fat and bone in children - where are we now?
}

Paul Dimitri. BSc, MBChB, $\mathrm{FRCPCH}, \mathrm{PhD}$

The University of Sheffield, Sheffield, United Kingdom
Received: 9 May, 2018

Accepted: 19 June, 2018

Address for correspondence:

Paul Dimitri

The Academic Unit of Child Health, Sheffield Children's NHS Foundation Trust, Western Bank, Sheffield S10 2TH, United Kingdom

Tel: $+44-271-7118$

Fax: +44-275-5364

E-mail: paul.dimitri@sch.nhs.uk

https://orcid.org/0000-0001-76256713
The risk of fracture secondary to low-impact trauma is greater in obese children, suggesting obese children are at risk of skeletal fragility. However, despite this finding, there is a lack of agreement about the impact of excessive adiposity on skeletal development. The combination of poor diet, sedentary lifestyle, greater force generated on impact through falls, and greater propensity to falls may in part explain the increased risk of fracture in obese children. To date, evidence suggests that in early childhood years, obesity confers a structural advantage to the developing skeleton. However, in time, this relationship attenuates and then reverses, such that there is a critical period during skeletal development when obesity has a detrimental effect on skeletal structure and strength. Fat mass may be important to the developing cortical and trabecular bone compartments, provided that gains in fat mass are not excessive. However, when fat accumulation reaches excessive levels, unfavorable metabolic changes may impede skeletal development. Evidence from studies examining bone microstructure suggests skeletal adaption to excessive load fails, and bone strength is relatively diminished in relation to body size in obese children. Mechanisms that may explain these changes include changes in the hormonal environment, particularly in relation to alterations in adipokines and fat distribution. Given the concomitant rise in the prevalence of childhood obesity and fractures, as well as adult osteoporosis, further work is required to understand the relationship between obesity and skeletal development.

Keywords: Obesity, Children, Bone mass, Bone density, Bone microstructure

\section{Introduction}

Over the last few decades, there has been a significant rise in the worldwide prevalence of childhood obesity, with a notable rise in several low and middle income countries. ${ }^{1,2)}$ In 2010 , 43 million children worldwide (35 million children in developing countries) were obese. The concomitant rise in the incidence of childhood forearm fractures ${ }^{3)}$ has led to a focus on the relationship between childhood obesity, bone mass, and fracture incidence. Causative explanations for this higher fracture risk include a greater propensity for falls, greater force upon fall impact, unhealthy lifestyle including poor diet and a reduction in physical activity, and excessive adipose tissue exerting direct or indirect detrimental effects on skeletal development. Importantly, bone mass acquired through childhood and adolescence tracks into adulthood, and may ultimately determine future osteoporotic risk. ${ }^{4,5)}$ Studies to date have focused on a number of key questions in an attempt to understand the impact of excess fat on bone development in children - (1) What is the impact of excess fat mass on bone mass and skeletal microstructure? (2) Does childhood obesity increase the risk of fracture? (3) What are the biological mechanisms underpinning the relationship between fat mass and bone mass in children and young people? (4) Does the relationship between childhood obesity and bone formation change during growth and development?

Despite a considerable body of bone densitometry data to date, the relationship between childhood obesity and bone remains controversial. Initial studies in this field suggested that 
rising fat mass improves bone mass, although this did not explain why obese children are over-represented in fracture groups. $^{6-9)}$ This observation led to an emerging body of evidence that fat mass may have a detrimental impact on bone mass when bone mass and body size were considered. Conflicting results between studies pointed towards the possibility of a changing relationship between fat and bone mass during growth and development. Specifically, the detrimental impact of childhood obesity on bone mass in children only occurred as fat mass accumulation reached excessive levels. Moreover, site-specific fat depots may account for the negative impact of excessive fat mass on bone development, similar to the increase in metabolic complications associated with visceral adiposity. The introduction of imaging modalities that generate information about bone microarchitecture and indices of bone strength has pointed towards a differential effect of excess fat mass on weight bearing and nonweight bearing sites, insights into the relationship between muscle mass and fat mass, and detailed alterations in the trabecular and cortical compartments observed in obese children. ${ }^{10)}$

\section{The assessment of bone structure and strength in children}

Bone mineral accretion in children is most commonly assessed by dual-energy x-ray absorptiometry (DXA), because of low radiation exposure, rapid scan time, availability of normative data, and widespread availability. ${ }^{11)}$ It generates a 2-dimensional planar image, providing measures of bone mineral content (BMC, g), areal bone mineral density (BMD, g/ $\left.\mathrm{cm}^{2}\right)$, and bone area $\left(\mathrm{cm}^{2}\right)$, and generates an age-specific $z$-score (standard deviation score). While it is readily available, DXA has technical limitations that lead to challenges in the assessment of bone mass in children. DXA is a 2-dimensional technique, which utilizes a planar image to estimate 3-dimensional structure. Thus, DXA provides a 2-dimensional areal rather than volumetric calculation of bone size and mass. Areal bone density $\left(\mathrm{g} / \mathrm{cm}^{2}\right)$ overestimates true bone density $\left(\mathrm{g} / \mathrm{cm}^{3}\right)$ in taller children with larger bones and underestimates true bone density in shorter children with smaller bones. ${ }^{12)}$ Given that nutritional obesity in children results in tall stature during growth, DXA will inherently overestimate age-specific bone density in this group. Conversely, when bone measurements are corrected for age in children whose body size is age-inappropriate, the interpretation of $z$-scores can lead to overdiagnosis of osteoporosis in smaller children. ${ }^{13)}$ Thus, studies utilizing DXA have attempted to overcome this issue by correcting for body size, although no agreement has been reached regarding the most reliable method to limit size-dependence for areal BMD. ${ }^{14,15)}$ DXA scanning of obese children and adults may result in additional inaccuracies due to tissue thickness resulting in an underestimation of bone mass, failure of the child to fit in the scanning field leads to position errors, and changes in body composition during growth that may impact on the longitudinal measurement of bone mass. ${ }^{15)}$

The introduction of peripheral quantitative computed tomo- graphy (pQCT) scanning and subsequently high-resolution PQCT (HRpQCT) has led to the ability to measure volumetric parameters of the cortical and trabecular compartments in vivo, and can evaluate indices of bone strength. The calculation of bone strength index at metaphyseal sites and strength-strain index at diaphyseal sites by PQCT have previously been shown to predict up to $85 \%$ of the variance in bone failure properties in human cadaveric tissues. ${ }^{16)}$ In particular, HRpQCT, with a spatial resolution of $64 \mu \mathrm{m}$, provides a means of virtual invivo 'noninvasive bone biopsy' of the distal radius and tibia, permitting the evaluation of cortical and trabecular volumetric components, trabecular connectivity, thickness and spacing, and cortical porosity. Finite element analysis (FEA) is an applied computerized model for predicting how an object reacts to 'real-world' forces and other physical effects, assessing the force required to overload or break the object. FEA works by breaking down a real object into a large number (thousands to hundreds of thousands) of finite elements. Mathematical equations then help to predict the behavior of each element. Computerized algorithms are then applied to all the individual behaviors to predict the overall behavior of the object. The application of $\mu$ FEA used to determine the biomechanical properties of the distal radius and tibia supports greater insight into bone strength and fracture risk in children ${ }^{17,18)}$ and has been used to assess the impact of fat and obesity on bone microrchitectural development and strength during growth. ${ }^{19)}$

\section{Obesity and fractures in children and young people}

Concerns that excess fat mass may have a detrimental effect on bone development in children originated from observations that obese children were overrepresented in fracture groups, ${ }^{6,7,20-23)}$ are at a greater risk of fracture, ${ }^{24)}$ and that the risk of repeated fracture is increased. ${ }^{6,25}$ At a pragmatic level, this was thought to be due to the observed abnormalities in gait, increasing the incidence of falls, thus resulting in greater force through the forearm and resultant fracture in obese children. ${ }^{26-29)}$ Earlier cross-sectional studies utilizing DXA suggested a negative relationship between obesity and bone mass in children, ${ }^{6,20-23,30)}$ although these findings have not been consistent with other studies demonstrating fat mass is either positively ${ }^{31,32)}$ or unrelated to bone mass or density. ${ }^{33,34)}$ Increased fracture risk and low bone mass in obese children may be exacerbated by poor dietary intake of calcium and vitamin $\mathrm{D}$, and a more sedentary lifestyle. ${ }^{35-37)}$ Given that the incidence of childhood fracture irrespective of body composition is greatest during adolescence and in males, then the impact of fat mass on skeletal development should be considered in the context of sex and age. Forearm fractures peak at mid to late puberty, possibly due to a transient increase in cortical porosity with a reduction in the ratio of cortical to trabecular bone in the forearm and an increase in cortical loading during the pubertal growth spurt ${ }^{17,38,39)}$; peak fracture incidence coincides with these cortical changes. Recent work using HRpQCT has demonstrated that children who sustain forearm fractures due to mild trauma have significant deficits in bone strength at the distal radius 
and significantly thinner metaphyseal cortices. ${ }^{18)}$ Further work is required at different stages of growth and development to determine whether skeletal microstructural changes predispose to skeletal fragility in obese children leading to an increased risk of fracture upon low impact.

\section{The relationship between fat and bone in children}

When studying the effect that increasing body mass has on children's bones, 2 outcomes need to be considered: (1) the relative influence that increasing fat mass or lean mass have on the size, geometry, mineral content, and architecture of bones, and (2) whether these changes confer a structural disadvantage, leading to increased fracture risk. Peak bone mass is achieved by early adulthood, may determine fracture risk in adults, ${ }^{40)}$ and is predicted to delay the onset of osteoporosis in later life by up to 13 years. ${ }^{41)}$ Thus, factors that negatively impact on peak bone mass accrual during adolescence may result in an increased risk of fracture and osteoporosis. Due to the significant influence of heredity and genes on skeletal development, bone mass 'tracks' during growth and development. ${ }^{42)}$ Alteration in body composition during childhood has been shown to lead to a deviation from predicted bone mass tracking. Higher lean mass increases the odds that spinal bone and hip density in boys and girls deviates positively from the normal 'tracking' trajectory. Conversely, an increase in the percentage of fat mass either limits the positive influence of lean mass, or results in a negative deviation from normal bone mass tracking in both sexes. ${ }^{43}$ Cross-sectional and longitudinal studies demonstrate that the relationship between fat mass and bone may vary according to age and skeletal development suggesting that the deviation from normal bone mass trajectory in relation to excess adiposity may be confined to specific periods during growth and development. During the first year of life, both fat and lean mass are associated with gain in total body BMC in both sexes ${ }^{44)}$ with this relationship persisting in prepubertal children. ${ }^{32)}$ As children approach puberty the positive relationship between excessive fat mass and bone mass appears to attenuate, and then reverses, albeit this change may be confined to females. ${ }^{45,46)}$ Moreover, the negative impact of obesity on bone mass during childhood may occur earlier in certain ethnic groups ${ }^{47)}$ or as a result of a consistently unhealthy lifestyle ${ }^{48)}$, which may persist into early adulthood. ${ }^{25}{ }^{\circ}$

The comparison of bone mass between obese and normalweight children leads to challenges as obese children reach their peak height velocity and thus peak bone mass accrual at an earlier age than lean children of the same age. Thus, obese children are taller than normal-weight children during growth and as a result will present with an apparently greater bone density. A further consideration in studies comparing the bone mass of lean and obese children relates to the earlier onset of peak height velocity in females corresponding to an earlier onset of puberty. ${ }^{49)}$ To overcome the impact that body size has on the estimation of bone mass assessment using DXA in children, several adjustment procedures have been used in previous studies. These include the Mølgaard/Cole model, which uses a 3-stage approach to calculate height for age, bone area for height, and BMC for bone area, ${ }^{50)}$ the use of multiple regression models incorporating measures of body size and age, ${ }^{30,51)}$ correcting BMC for lean mass, ${ }^{52)}$ creating $z$-scores for weight and height, ${ }^{30,53)}$ and using algorithms that covert areal to volumetric measures. ${ }^{30)}$ Despite attempts to overcome the inherent challenges in using DXA to compare difference in bone mass between lean and obese children, the conflicting results between studies has led to a more detailed assessment of skeletal structure and strength, and thus, bone quality to gain further insight into the higher incidence of fracture in obese children. Studies using either conventional CT or pQCT suggest a possible site-specific variation in bone size and strength between obese and lean children. Conventional CT imaging of 300 adolescent males and females did not demonstrate a relationship between total body fat mass and vertebral size. ${ }^{54)}$ In contrast, pQCT imaging confined to late adolescent females reported that a higher body fat mass percentage was associated with a significantly smaller bone size and lower cortical bone strength at the radius and tibia. ${ }^{55)}$ As with DXA studies, outcomes from pQCT studies are conflicting. Others have demonstrated that overweight children (body mass index $[\mathrm{BMI}]>85$ th percentile) at an earlier stage in puberty have greater indices of bone strength measured by pQCT and that bone strength is adapted to lean rather than fat mass.

The difference between studies suggests the need to consider the stage of development at which bone strength is assessed and the degree of adiposity, which may also relate to pathogenic changes in metabolic profile. Greater longitudinal gain in fat mass during puberty appears to have a negative effect on the cortex of the appendicular skeleton with reductions observed in cortical BMD, thickness, and area with increasing fat mass. ${ }^{46)}$ Thus, while an increase in lean mass observed in obese children may augment bone strength in early years, the pathological accumulation of fat over time may lead to a diminished effect of muscle mass on bone, and eventually a detrimental impact on bone structure and strength as children progress to later puberty. Furthermore, a curvilinear relationship appears to exist between the quantity of fat mass and bone quantity and strength. At much lower fat mass, bone quantity and strength are reduced as demonstrated in studies of children and adults with anorexia nervosa. ${ }^{56)}$ Indices of bone quantity and strength improve as fat and lean mass rises, before reaching a 'fat threshold' at which additional fat imparts a deleterious effect on the growing skeleton. ${ }^{47,57)}$ Fat distribution may also be fundamental in determining bone quality and strength, reflecting a similar relationship observed between visceral adiposity, and cardiovascular and metabolic comorbidities. ${ }^{58,59)}$ Visceral fat appears to result in a lower total body and lumbar bone mineral density in children, ${ }^{60)}$ and bone density at weight bearing sites, ${ }^{57,61)}$ which may be related to the presence of evolving metabolic complications. ${ }^{62)}$ Thus, the development of central adiposity over time may account for the deleterious effect that fat mass has on bone quality and strength observed in studies that recruit children during adolescence who have a higher BMI. The accumulation of fat in skeletal muscle may also serve as another pathogenic fat depot that could impact bone strength in the developing skeleton. Studies in adults 
demonstrate that a greater fat content within skeletal muscle predicts hip fracture. ${ }^{63,64)}$ Moreover, like visceral adiposity, increased fat within skeletal muscle, specifically intramyocellular fat stores, is associated with impaired glucose tolerance and type 2 diabetes. ${ }^{65,66)}$ Further work is needed to determine the impact of skeletal muscle fat on bone in children. However, emerging evidence suggests that skeletal muscle fat may serve as another pathogenic fat depot on trabecular bone development in children, ${ }^{67)}$ and that this may be a risk factor for skeletal fragility and fracture. ${ }^{68)}$

Results from HRpQCT studies provide further insight into the impact of childhood obesity on the microarchitectural changes observed in the developing skeleton. In comparison between lean and obese children, Dimitri et al. ${ }^{19)}$ demonstrated microarchitectural reorganization of bone was primarily confined to the trabecular compartment in obese children. In comparison with normal-weight children, obese children had thinner trabeculae, but the trabeculae were greater in number and more closely spaced, although this finding was confined to the distal tibia. Further evidence suggested that these tibial trabecular changes may result in a reduction in skeletal strength. Consistent with work published by Farr et al. ${ }^{69)}$ there was no difference in cortical or trabecular microstructural parameters between lean and obese children. Furthermore, indices of strength assessed by microfinite element analysis at the radius were not different between the 2 groups, suggesting that the strength of the distal radius does not commensurately increase with excessive gains in fat mass during growth. This potentially leads to a mismatch between the strength of the radius and the load experienced by the distal forearm during a fall, a load which is greater in obese individuals in part explaining why obese children are more prone to fracture. Thus, in the future, carefully designed longitudinal studies are required to determine the impact of excessive fat mass on bone that take into account the age and sex of the children studied, their stage of puberty, the quantity and distribution of fat mass, and adverse metabolic parameters that may influence skeletal changes.

\section{Childhood obesity, adipokines, and skeletal development}

Adipokines are cytokines secreted by adipose tissue. Of those that have been discovered, leptin and adiponectin appear to have both a direct and centrally mediated influence on skeletal metabolism. Earlier in vitro and in vivo studies demonstrated that leptin acts directly via osteoblast receptors on human marrow stromal cells to promote osteoblast proliferation and differentiation, ${ }^{70)}$ while inhibiting adipocyte differentiation and osteoclastogenesis through generation of osteoprotegerin. ${ }^{71,72)}$ In contrast, in vivo studies in tail-suspended rats demonstrated that the amount of fat and thus leptin, may have a dose-mediated effect on skeletal metabolism; lower concentrations of leptin appear to be osteoprotective, but at higher concentrations, bone loss is increased by bone resorption and reduced bone formation. ${ }^{73)}$ Thus, the curvilinear relationship between escalating fat mass and skeletal architecture described earlier appears to be mimicked by escalating concentrations of leptin, thereby pointing to a possible direct role of leptin in skeletal metabolism in children and adolescents. Furthermore, this relationship may explain why in studies of obese children, high levels of circulating leptin are associated with a reduction in bone mass, trabecular thickness, and an increase in cortical porosity, ${ }^{19,30,74)}$ but in studies of children of normal body weight, the same relationship is not observed. ${ }^{70,75,76)}$ Studies in animal models demonstrate centrally mediated control of skeletal metabolism by leptin. Earlier studies pointed towards leptin exerting an antiosteogenic effect through a sympathetic hypothalamic relay. ${ }^{77)}$ Such a relationship was supported by evidence that patients with reflex sympathetic dystrophy, a disease characterized by high sympathetic tone, are prone to low bone mass, yet some cases can be mitigated by beta-blockers. ${ }^{78)}$ However, subsequent evidence emerged that sympathetic efferent pathways emerging from the hypothalamus had regulatory control of skeletal metabolism by also inhibiting osteoblast proliferation via circadian clock genes, ${ }^{79)}$ and that the sympathetic nervous system also favors bone resorption by increasing the expression of RANKL. ${ }^{80)}$ In humans, evidence that leptin may mediate central control of bone mass comes from studies of children with congenital leptin deficiency. Children with congenital leptin deficiency are markedly obese, yet they present with normal age- and sex-related wholebody BMD, despite also presenting with hypogonadism and hyperparathyroidism. ${ }^{81,82)}$ This finding supports the possibility that leptin deficiency may act centrally to confer a protective effect on the developing skeleton in a hormonal environment that should result in low bone mass, and is further supported by the finding that 2 children with congenital leptin deficiency were found to have a high bone mass phenotype. ${ }^{83)}$

Adiponectin is a hormone involved in regulating glucose levels, as well as fatty acid breakdown. In humans it is encoded by the $A D I P O Q$ gene and is produced in adipose tissue. However, in contrast to leptin, circulating adiponectin levels decrease with increasing fat mass. ${ }^{84)}$ Adiponectin appears to have a protective effect in various processes such as energy metabolism, inflammation, and cell proliferation. ${ }^{84)}$ Adiponectin deficiency in mice negatively impacts cortical and trabecular compartments, ${ }^{85)}$ but in children and adults, an inverse relationship exists between adiponectin and bone. ${ }^{86-88)}$ Thus, in obesity, a lower serum adiponectin level may protect the skeleton, a finding which appears to contradict the metabolically protective effect that high levels of leptin have in leaner individuals. However, animal studies suggest that the impact of adiponectin on bone mass may be age-related, due to a switch in the action of adiponectin from peripheral to central over time. ${ }^{89)}$ Adiponectin knockout mice have a high bone mass resulting from increased bone formation. However, over time, they develop severe low bone mass. This was explained by the fact that early on, adiponectin acts directly on osteoblasts to prevent their proliferation and increase osteoblast apoptosis, but over time, this action is obscured by adiponectin signaling centrally in the neurons of the locus coeruleus to decrease sympathetic tone. As a result, increasing bone mass and decreasing energy expenditure occurs, thus partially opposing leptin's central influence on the sympathetic nervous system. ${ }^{90)}$ Other adipo- 
kines have been implicated in the regulation of bone mass and are described elsewhere, ${ }^{91,92)}$ although the relationship of these adipocytokines with bone parameters in obese children is unknown.

\section{Future directions}

Previous studies examining the relationship between excessive adiposity and skeletal development in children demonstrate a number of challenges that should be addressed in future studies. The developing skeleton is exposed to alterations in hormones, particularly during puberty, that are affected by increasing adiposity. As obese children enter puberty and reach final adult height and peak bone mass accrual at an earlier stage, comparing skeletal parameters in normal weight and obese children is challenging. Moreover, the difference in hormonal patterns between developing males and females together with differences in the timing of peak height velocity demonstrate the need to adopt a sex-specific approach in assessing the impact of fat mass on bone in children and adolescents. Future prospective extended longitudinal studies of both weight-bearing and non-weight-bearing skeletal sites are necessary to examine the site-specific differences in the effects of fat on bone in males and females. Careful consideration is required to determine whether the negative impact of obesity on skeletal development is confined to pathogenic fat depots, and whether excessive fat mass results in alterations in skeletal microarchitecture and strength that results in skeletal fragility and fracture. Identifying factors that may lead to skeletal fragility and the period of development during which these factors have their greatest impact will help to refine approaches to improve skeletal health, and thus reduce the higher incidence of fractures in obese children.

The advent of HRpQCT has provided a noninvasive approach to understand changes in cortical and trabecular microarchitecture and strength during skeletal development, and a means to assess endogenous and exogenous factors that may alter skeletal integrity and strength. However, HRpQCT measurements are confined to the distal $9 \mathrm{~mm}$ of the radius and the tibia, and may not necessarily reflect changes occurring at proximal appendicular sites and central skeletal sites, such as the vertebrae. Additionally, HRpQCT poses additional challenges in children as the site measured changes as children grow, making comparative studies between different age groups challenging. pQCT provides a means of overcoming these challenges in the proximal appendicular skeleton, but is limited by resolution when assessing trabecular compartments. The use of magnetic resonance imaging (MRI) to assess peripheral and central skeletal sites may help to overcome these issues with the added value of posing no radiation risk. The use of magnetic resonance ultrashort time echo sequences has enabled the quantification of cortical bone parameters based upon cortical bone water concentration and cortical bone porosity. ${ }^{93,94)}$ More recently, engineering models have been applied to the textural features of the trabecular envelope using multiple MRI sequences, demonstrating a close correlation between trabecular microstructural parameters assessed by HRpQCT. ${ }^{95)}$ Thus, the future development of MRI sequences in combination with novel approaches to image analysis may provide an additional method of assessing factors that impact bone microstructure and strength at other skeletal sites.

\section{Conclusions}

Studies to date clearly suggest that obesity during childhood has the potential to drive deviation away from genetically predicted skeletal development. However, limitations with imaging modalities, challenges with longitudinal studies, and differences in age, sex, and degree of adiposity between cohorts has resulted in conflicting results. Collectively, evidence points towards a fat mass threshold, which if exceeded during critical points in skeletal development, particularly adolescence, may result in skeletal fragility and ultimately increased fracture risk. This threshold is not known and could vary by age and pubertal development, but may be determined by deposition of fat in sites associated with other metabolic consequences such as visceral and muscle fat depots. In turn, changes in adipokines and other hormones may precipitate an alteration in skeletal architecture that limits the positive impact that lean mass imparts on bone, or may directly impact bone development and metabolism. While this field of research has led to greater insight into the relationship between childhood obesity and bone, in a society where childhood obesity has become more prevalent, further work is required to understand how the developing skeleton changes in response to escalating fat mass, when and why these changes occur, and the resulting risks.

\section{Conflict of interest}

No potential conflict of interest relevant to this article was reported.

\section{References}

1. Wang Y, Lobstein T. Worldwide trends in childhood overweight and obesity. Int J Pediatr Obes 2006;1:11-25

2. Lobstein T, Jackson-Leach R, Moodie ML, Hall KD, Gortmaker SL, Swinburn BA, et al. Child and adolescent obesity: part of a bigger picture. Lancet 2015;385:2510-20.

3. Khosla S, Melton LJ 3rd, Dekutoski MB, Achenbach SJ, Oberg AL, Riggs BL. Incidence of childhood distal forearm fractures over 30 years: a population-based study. JAMA 2003;290:1479-85.

4. Bass S, Delmas PD, Pearce G, Hendrich E, Tabensky A, Seeman E. The differing tempo of growth in bone size, mass, and density in girls is region-specific. J Clin Invest 1999; 104:795-804.

5. Matkovic V, Jelic T, Wardlaw GM, Iliac JZ, Goes PK, Wright JK, et al. Timing of peak bone mass in Caucasian females and its implication for the prevention of osteoporosis Inference from a cross-sectional model. J Clin Invest 1994;93:799-808. 
6. Goulding A, Grant AM, Williams SM. Bone and body composition of children and adolescents with repeated forearm fractures. J Bone Miner Res 2005;20:2090-6.

7. Manias K, McCabe D, Bishop N. Fractures and recurrent fractures in children; varying effects of environmental factors as well as bone size and mass. Bone 2006;39:652-7.

8. Fornari ED, Suszter M, Roocroft J, Bastrom T, Edmonds EW, Schlechter J. Childhood obesity as a risk factor for lateral condyle fractures over supracondylar humerus fractures. Clin Orthop Relat Res 2013;471:1193-8.

9. Kessler J, Koebnick C, Smith N, Adams A. Childhood obesity is associated with increased risk of most lower extremity fractures. Clin Orthop Relat Res 2013;471:1199207.

10. Farr JN, Dimitri P. The impact of fat and obesity on bone microarchitecture and strength in children. Calcif Tissue Int 2017;100:500-13.

11. Gordon CM, Bachrach LK, Carpenter TO, Crabtree N, El-Hajj Fuleihan G, Kutilek S, et al. Dual energy X-ray absorptiometry interpretation and reporting in children and adolescents: the 2007 ISCD pediatric official positions. J Clin Densitom 2008;11:43-58.

12. Fewtrell MS; British Paediatric \& Adolescent Bone Group. Bone densitometry in children assessed by dual $\mathrm{X}$ ray absorptiometry: uses and pitfalls. Arch Dis Child 2003;88:795-8.

13. Gafni RI, Baron J. Overdiagnosis of osteoporosis in children due to misinterpretation of dual-energy $\mathrm{x}$-ray absorptiometry (DEXA) J Pediatr 2004;144:253-7.

14. Dimitri P, Bishop N, Walsh JS, Eastell R. Obesity is a risk factor for fracture in children but is protective against fracture in adults: a paradox. Bone 2012;50: 457-66.

15. Kelley JC, Crabtree N, Zemel BS. Bone density in the obese child: clinical considerations and diagnostic challenges. Calcif Tissue Int. 2017;100:514-27.

16. Kontulainen SA, Johnston JD, Liu D, Leung C, Oxland TR, McKay HA. Strength indices from pQCT imaging predict up to $85 \%$ of variance in bone failure properties at tibial epiphysis and diaphysis. J Musculoskelet Neuronal Interact 2008;8:401-9.

17. Kirmani S, Christen D, van Lenthe GH, Fischer PR, Bouxsein ML, McCready LK, et al. Bone structure at the distal radius during adolescent growth. J Bone Miner Res 2009;24:1033-42.

18. Farr JN, Amin S, Melton LJ 3rd, Kirmani S, McCready LK, Atkinson EJ et al. Bone strength and structural deficits in children and adolescents with a distal forearm fracture resulting from mild trauma. J Bone Miner Res 2014;29:5909.

19. Dimitri P, Jacques RM, Paggiosi M, King D, Walsh J, Taylor ZA, et al. Leptin may play a role in bone microstructural alterations in obese children. J Clin Endocrinol Metab 2015;100:594-602.

20. Goulding A, Jones IE, Taylor RW, Manning PJ, Williams SM. More broken bones: a 4-year double cohort study of young girls with and without distal forearm fractures. J Bone
Miner Res 2000;15:2011-8.

21. Goulding A, Cannan R, Williams SM, Gold EJ, Taylor RW, Lewis-Barned NJ. Bone mineral density in girls with forearm fractures. J Bone Miner Res 1998;13:143-8.

22. Goulding A, Jones IE, Taylor RW, Williams SM, Manning PJ. Bone mineral density and body composition in boys with distal forearm fractures: a dual-energy x-ray absorptiometry study. J Pediatr 2001;139:509-15.

23. Goulding A, Taylor RW, Jones IE, McAuley KA, Manning PJ, Williams SM. Overweight and obese children have low bone mass and area for their weight. Int J Obes Relat Metab Disord 2000;24:627-32.

24. Kim SJ, Ahn J, Kim HK, Kim JH. Obese children experience more extremity fractures than nonobese children and are significantly more likely to die from traumatic injuries. Acta Paediatr 2016;105:1152-7.

25. Jones IE, Taylor RW, William SM, Manning P, Goulding A. Four-year gain in bone mineral in girls with and without past forearm fractures: a DXA study. J Bone Miner Res 2002;17:1065-72.

26. Goulding A, Jones IE, Taylor RW, Piggot JM, Taylor D. Dynamic and static tests of balance and postural sway in boys: effects of previous wrist bone fractures and high adiposity. Gait Posture. 2003;17:136-41

27. Hue O, Simoneau M, Marcotte J, Kerrigan F, Dore J, Marceau P, et al. Body weight is a strong predictor of postural stability. Gait Posture 2007;26:32-8.

28. McGraw B, McClenaghan BA, Williams HG, Dickerson J, Ward DS. Gait and postural stability in obese and nonobese prepubertal boys. Arch Phys Med Rehab 2000;81:484-9.

29. Frost HM .Obesity, and bone strength and "mass": a tutorial based on insights from a new paradigm. Bone 1997;21:2114.

30. Dimitri P, Wales J, Bishop N. Fat and bone in children: differential effects of obesity on bone size and mass according to fracture history. J Bone Miner Res 2010;25:527-36

31. Leonard MB, Shults J, Wilson BA, Tershakovec AM, Zemel BS .Obesity during childhood and adolescence augments bone mass and bone dimensions. Am J Clin Nutr 2004;80:514-23.

32. Clark EM, Ness AR, Tobias JH. Adipose tissue stimulates bone growth in prepubertal children. J Clin Endocrinol Metab 2006;91:2534-41.

33. Manzoni P, Brambilla P, Pietrobelli A, Beccaria L, Bianchessi A, Mora S, et al. Influence of body composition on bone mineral content in children and adolescents. Am J Clin Nutr. 2006;64:603-7.

34. Petit MA, Beck TJ, Shults J, Zemel BS, Foster BJ, Leonard MB. Proximal femur bone geometry is appropriately adapted to lean mass in overweight children and adolescents. Bone 2005;36:568-76.

35. Wosje KS, Khoury PR, Claytor RP, Copeland KA, Hornung RW, Daniels SR, et al. Dietary patterns associated with fat and bone mass in young children. Am J Clin Nutrit 2010;92:294-303 
36. Plesner JL, Dahl M, Fonvig CE, Nielsen TRH, Kloppenborg JT, Pedersen O, et al. Obesity is associated with vitamin D deficiency in Danish children and adolescents. J Pediatr Endocrinol Metab 2018;31:53-61.

37. Black RE, Williams SM, Jones IE, Goulding A. Children who avoid drinking cow milk have low dietary calcium intakes and poor bone health. Am J Clin Nutrit 2002;76:675-80.

38. Bailey DA, Wedge JH, McCulloch RG, Martin AD, Bernhardson SC. Epidemiology of fractures of the distal end of the radius in children as associated with growth. J Bone Joint Surg 1989;71:1225-31.

39. Wang Q, Wang XF, Iuliano-Burns S, Ghasem-Zadeh A, Zebaze R, Seeman E. Rapid growth produces transient cortical weakness: a risk factor for metaphyseal fractures during puberty. J Bone Miner Res 2010;25:1521-6.

40. Heaney RP, Abrams S, Dawson-Hughes B, Looker A, Marcus R, Matkovic V, et al. Peak bone mass. Osteoporos Int 2000;11:985-1009.

41. Hernandez CJ, Beaupre' GS, Carter DR. A theoretical analysis of the relative influences of peak BMD, agerelated bone loss and menopause on the development of osteoporosis. Osteoporos Int 2003;14:843-7.

42. Havill LM, Mahaney MC, Binkley TL, Specker BL. Effects of genes, sex, age, and activity on BMC, bone size, and areal and volumetric BMD. J Bone Miner Res 2007;22:737-46.

43. Foley S, Quinn S, Jones G. Tracking of bone mass from childhood to adolescence and factors that predict deviation from tracking. Bone 2009;44:752-7.

44. Sudhagoni RG, Wey HE, Djira GD, Specker BL. Longitudinal effects of fat and lean mass on bone accrual in infants. Bone 2012;50:638-42.

45. Sayers A, Marcus M, Rubin C, McGeehin MA, Tobias $\mathrm{JH}$. Investigation of sex differences in hip structure in peripubertal children. J Clin Endocrinol Metab 2010;95:3876-83.

46. Wey HE, Binkley TL, Beare TM, Wey CL, Specker BL. Cross-sectional versus longitudinal associations of lean and fat mass with pQCT bone outcomes in children. J Clin Endocrinol Metab 2011;96:106-14.

47. Burrows M, Baxter-Jones A, Mirwald R, Macdonald H, McKay H. Bone mineral accrual across growth in a mixedethnic group of children: are Asian children disadvantaged from an early age? Calcif Tissue Int. 2009;84:366-78.

48. Wosje KS, Khoury PR, Claytor RP, Copeland KA, Kalkwarf HJ, Daniels SR. Adiposity and TV viewing are related to less bone accrual in young children. J Pediatr 2009;154:79-85. e72.

49. Chumlea WC, Siervogel RM, Roche AF, Webb P, Rogers E. Increments across age in body composition for children 10 to 18 years of age. Hum Biol 1983;55:845-52

50. Mølgaard C, Thomsen BL, Prentice A, Cole TJ, Michaelsen KF. Whole body bone mineral content in healthy children and adolescents. Arch Disease Child 1997;76:9-15.

51. Hannan WJ, Cowen SJ, Wrate RM, Barton J. Improved prediction of bone mineral content and density. Arch Disease Child 1995;72:147-9.
52. Crabtree NJ, Kibirige MS, Fordham JN, Banks LM, Muntoni F, Chinn D, et al. The relationship between lean body mass and bone mineral content in paediatric health and disease. Bone 2004;35:965-72.

53. Webber CE, Sala A, Barr RD. Accounting for body size deviations when reporting bone mineral density variables in children. Osteoporos Int 2009;20:113-21.

54. Janicka A, Wren TA, Sanchez MM, Dorey F, Kim PS, Mittelman SD, et al. Fat mass is not beneficial to bone in adolescents and young adults. J Clin Endocrinol Metab 2007;92:143-7.

55. Pollock NK, Laing EM, Baile CA, Hamrick MW, Hall DB, Lewis RD. Is adiposity advantageous for bone strength? A peripheral quantitative computed tomography study in late adolescent females. Am J Clin Nutr 2007;86:1530-8.

56. Misra M, Klibanski A. Anorexia nervosa and bone. J Endocrinol 2014;221:R163-76.

57. Laddu DR, Farr JN, Laudermilk MJ, Lee VR, Blew RM, Stump C, et al. Longitudinal relationships between whole body and central adiposity on weight-bearing bone geometry, density, and bone strength: a pQCT study in young girls. Arch Osteoporos 2013;8:156.

58. Koster A, Stenholm S, Alley DE, Kim LJ, Simonsick EM, Kanaya AM, et al. Body fat distribution and inflammation among obese older adults with and without metabolic syndrome. Obesity (Silver Spring) 2010;18:2354-61.

59. Shah RV, Murthy VL, Abbasi SA, Blankstein R, Kwong RY, Goldfine AB et al. Visceral adiposity and the risk of metabolic syndrome across body mass index: the MESA Study. JACC Cardiovasc Imaging. 2014;7:1221-35.

60. Russell M, Mendes N, Miller KK, Rosen CJ, Lee H, Klibanski A, et al. Visceral fat is a negative predictor of bone density measures in obese adolescent girls. J Clin Endocrinol Metab 2010;95:1247-55.

61. Gilsanz V, Chalfant J, Mo AO, Lee DC, Dorey FJ, Mittelman SD. Reciprocal relations of subcutaneous and visceral fat to bone structure and strength. J Clin Endocrinol Metab 2009;94:3387-93.

62. Pollock NK, Bernard PJ, Wenger K, Misra S, Gower $\mathrm{BA}$, Allison JD, et al. Lower bone mass in prepubertal overweight children with prediabetes. J Bone Miner Res 2010;25:2760-9.

63. Lang T, Koyama A, Li C, Li J, Lu Y, Saeed I, et al. Pelvic body composition measurements by quantitative computed tomography: association with recent hip fracture. Bone 2008;42:798-805.

64. Lang T, Cauley JA, Tylavsky F, Bauer D, Cummings S, Harris TB, et al. Computed tomographic measurements of thigh muscle cross-sectional area and attenuation coefficient predict hip fracture: the health, aging, and body composition study. J Bone Miner Res 2010;25:513-9.

65. Sinha R, Dufour S, Petersen KF, LeBon V, Enoksson S, Ma $\mathrm{YZ}$, et al. Assessment of skeletal muscle triglyceride content by (1)H nuclear magnetic resonance spectroscopy in lean and obese adolescents: relationships to insulin sensitivity, total body fat, and central adiposity. Diabetes 2002;51:1022- 
7.

66. Pan DA, Lillioja S, Kriketos AD, Milner MR, Baur LA, Bogardus C, et al. Skeletal muscle triglyceride levels are inversely related to insulin action. Diabetes 1997;46:983-8.

67. Farr JN, Funk JL, Chen Z, Lisse JR, Blew RM, Lee VR, et al. Skeletal muscle fat content is inversely associated with bone strength in young girls. J Bone Miner Res 2011;26:2217-25.

68. Farr JN, Tomás R, Chen Z, Lisse JR, Lohman TG, Going SB. Lower trabecular volumetric BMD at metaphyseal regions of weight-bearing bones is associated with prior fracture in young girls. J Bone Miner Res 2011;26:380-7.

69. Farr JN, Amin S, LeBrasseur NK, Atkinson EJ, Achenbach SJ, McCready LK, et al. Body composition during childhood and adolescence: relations to bone strength and microstructure. J Clin Endocrinol Metab 2014;99:4641-8.

70. Roemmich JN, Clark PA, Mantzoros CS, Gurgol CM, Weltman A, Rogol AD. Relationship of leptin to bone mineralization in children and adolescents. J Clin Endocrinol Metab 2003;88:599-604

71. Thomas T, Gori F, Khosla S, Jensen MD, Burguera B, Riggs BL. Leptin acts on human marrow stromal cells to enhance differentiation to osteoblasts and to inhibit differentiation to adipocytes. Endocrinology 1999;140:1630-8.

72. Holloway WR, Collier FM, Aitken CJ, Myers DE, Hodge JM, Malakellis M, et al. Leptin inhibits osteoclast generation. J Bone Miner Res 2002;17:200-9.

73. Martin A, David V, Malaval L, Lafage-Proust MH, Vico L, Thomas T. Opposite effects of leptin on bone metabolism: a dose-dependent balance related to energy intake and insulin-like growth factor-I pathway. Endocrinology 2007;148:3419-25.

74. Afghani A, Goran MI. The interrelationships between abdominal adiposity, leptin and bone mineral content in overweight Latino children. Horm Res 2009;72:82-7.

75. Garnett SP, Hogler W, Blades B, Baur LA, Peat J, Lee J, et al. Relation between hormones and body composition, including bone, in prepubertal children. Am J Clin Nutr 2004;80:966-72.

76. Huang KC, Cheng WC, Yen RF, Tsai KS, Tai TY, Yang WS. Lack of independent relationship between plasma adiponectin, leptin levels and bone density in nondiabetic female adolescents. Clin Endocrinol (Oxf) 2004;61:204-8.

77. Elefteriou F, Ahn JD, Takeda S, Starbuck M, Yang X, Liu X, et al. Leptin regulation of bone resorption by the sympathetic nervous system and CART. Nature. 2005;434:514-20.

78. Schwartzman RJ. New treatments for reflex sympathetic dystrophy. N Engl J Med 2000;343:654-6.

79. Fu L, Patel MS, Bradley A, Wagner EF, Karsenty G. The molecular clock mediates leptin-regulated bone formation. Cell 2005;122:803-15.

80. Kondo H, Togari A. Continuous treatment with a lowdose beta-agonist reduces bone mass by increasing bone resorption without suppressing bone formation. Calcif Tissue Int 2011;88:23-32.

81. Montague CT, Farooqi IS, Whitehead JP, Soos MA, Rau $\mathrm{H}$, Wareham NJ, et al. Congenital leptin deficiency is associated with severe early-onset obesity in humans. Nature 1997;387:903-8.

82. Farooqi IS, Jebb SA, Langmack G, Lawrence E, Cheetham $\mathrm{CH}$, Prentice AM, et al. Effects of recombinant leptin therapy in a child with congenital leptin deficiency. N Engl J Med 1999;341:879-84.

83. Hannema SE, Wit JM, Houdijk ME, van Haeringen A, Bik EC, Verkerk AJ, et al. Novel leptin receptor mutations identified in two girls with severe obesity are associated with increased bone mineral density. Horm Res Paediatr 2016;85:412-20.

84. Nigro E, Scudiero O, Ludovica Monaco M, Palmieri A, Mazzarella G, Costagliola C, et al. New insight into adiponectin role in obesity and obesity-related diseases. Biomed Res Int 2014;2014:658913.

85. Naot D, Watson M, Callon KE, Tuari D, Musson DS, Choi $\mathrm{AJ}$, et al. Reduced bone density and cortical bone indices in female adiponectin-knockout mice. Endocrinology 2016;157:3550-61.

86. Lenchik L, Register TC, Hsu FC, Lohman K, Nicklas BJ, Freedman BI, et al. Adiponectin as a novel determinant of bone mineral density and visceral fat. Bone 2003;33:646-51.

87. Richards JB, Valdes AM, Burling K, Perks UC, Spector TD. Serum adiponectin and bone mineral density in women. J Clin Endocrinol Metab 2007;92:1517-23.

88. Johansson H, Oden A, Karlsson MK, McCloskey E, Kanis JA, Ohlsson C, et al. Waning predictive value of serum adiponectin for fracture risk in elderly men: MrOS Sweden. Osteoporos Int 2014;25:1831-6.

89. Kajimura D, Lee HW, Riley KJ, Arteaga-Solis E, Ferron M, Zhou B, et al. Adiponectin regulates bone mass via opposite central and peripheral mechanisms through FoxO1. Cell 2013;17:901-15.

90. Dimitri P, Rosen C. The central nervous system and bone metabolism: an evolving story. Calcif Tissue Int 2017;100:476-85

91. Thommesen L, Stunes AK, Monjo M, Grosvik K, Tamburstuen MV, Kjobli E, et al. Expression and regulation of resistin in osteoblasts and osteoclasts indicate a role in bone metabolism. J Cell Biochem 2006;99:824-34.

92. Liu Y, Song CY, Wu SS, Liang QH, Yuan LQ, Liao EY. Novel adipokines and bone metabolism. Int J Endocrinol 2013;2013:895045

93. Li C, Seifert AC, Rad HS, Bhagat YA, Rajapakse CS, Sun W, et al. Cortical bone water concentration: dependence of MR imaging measures on age and pore volume fraction. Radiology 2014;272:796-806.

94. Rajapakse CS, Bashoor-Zadeh M, Li C, Sun W, Wright AC, Wehrli FW. Volumetric cortical bone porosity assessment with MR imaging: validation and clinical feasibility. Radiology 2015;276:526-35.

95. Lekadir K, Hoogendoorn C, Armitage P, Whitby E, King D, Dimitri P, et al. Estimation of trabecular bone parameters in children from multisequence MRI using texture-based regression. Med Phys 2016;43:3071-9. 